\title{
AS POLÍTICAS DE ACESSO E PERMANÊNCIA NA EDUCAÇÃo SUPERIOR: A BUSCA DA IGUALDADE DE RESULTADOS
}

\author{
GISI, Maria Lourdes ${ }^{1}$ \\ PEGORINI, Diana Gurgel ${ }^{2}$
}

\section{Resumo}

Este texto tem como objeto de estudo as políticas de acesso e a evasão na educação superior. Busca analisar os avanços relacionados à ampliação do acesso a esse nível de ensino e a permanência dos estudantes. A evasão é uma problemática que tem se agravado por razões tanto de ordem econômica como aquelas decorrentes da própria instituição. Em relação à instituição, existem as expectativas não atendidas dos estudantes, o modo como se realiza a integração no mundo acadêmico e as condições relacionadas ao processo pedagógico. Discute-se o papel das instituições de ensino no que se refere à implementação de ações que possam contribuir para diminuir a evasão a partir da concepção da igualdade dos resultados, portanto do acesso, permanência e conclusão da educação superior. Trata-se de um estudo que contempla uma análise documental, com base em documentos oficiais, legislação vigente e dados de organismos nacionais e internacionais. Contempla o contexto da educação superior e a efetividade das políticas em relação às iniciativas governamentais que se relacionam com as possibilidades de ampliar o acesso e favorecer a permanência na educação superior. Na sequência, analisase a educação superior na perspectiva da justiça social, de modo a diminuir as disparidades existentes.

Palavras-Chave: Educação Superior; Acesso e Permanência; Evasão.

\footnotetext{
${ }^{1}$ Professora Titular do Programa de Pós-Graduação em Educação da PUCPR. Bolsista Produtividade da Fundação Araucária/PR - Fundação de Apoio ao Desenvolvimento Científico e Tecnológico do Paraná. Email: maria.gisi@pucpr.br

${ }^{2}$ Professora do Instituto Federal do Paraná. Doutoranda em Educação do Programa de Pós-Graduação em Educação da PUCPR. E-mail: diana.pegorini@ifpr.edu.br
} 


\title{
ACCESS AND STAYING POLICIES IN HIGHER EDUCATION: THE SEARCH IN EQUALITY RESULTS
}

\author{
GISI, Maria Lourdes ${ }^{3}$ \\ PEGORINI, Diana Gurgel ${ }^{4}$
}

\begin{abstract}
This text has as study object access policies and evasion in higher education. It seeks to analyze the development related to the expansion of access to this level of teaching and the attention that it has been given to students' staying in universities. Evasion is a problem that has worsened for reasons both of economic order and those arriving from the institution itself. Regarding the institution, there are students' unmet expectations, the way how integration is performed in the academic world and the conditions related to the educational process. The role of the educational institutions is discussed regarding the implementation of actions that can help reduce evasion from the concept of the equality results, therefore access, stay and conclusion of higher education. It is a study that contemplates a documentary analysis, based on official documents, current legislation and data from national and international organizations. It contemplates the higher education context and the effectiveness of the policies regarding government initiatives that are related to the possibilities of expanding access and promoting staying in higher education. As a result, it analyzes higher education in the perspective of social justice, in order to reduce existing disparities.
\end{abstract}

Key words: Higher Education; Access and Staying; Evasion.

\section{Introdução}

A educação superior no país tem sido, no decorrer dos anos, para poucos, como já apontado por Oliveira (2013, p. 275) quando analisa o acesso ao ensino superior no Brasil Colônia, como sendo de "elitismo e conservadorismo", o que se mantém no Império, na Primeira República e na Era Vargas, quando os cursos de nível superior destinam-se à formação dos mais favorecidos economicamente. Se no período militar observa-se a ampliação do acesso no setor público, este também ocorreu de modo significativo no setor privado, segundo Shiroma et al. (2011), dificultando o acesso e a permanência para muitos.

Na década de 1990, com o aumento de cursos e instituições de educação superior,

${ }^{3}$ Full Professor of the Graduate Program in Education at PUCPR. Productivity Scholarship Holder at Araucária Foundation/PR - Scientific and Technological Development Support Foundation of Paraná. E-mail: maria.gisi@pucpr.br

${ }^{4}$ Professor at Federal Institute of Paraná. PhD Student in Education at the Graduate Program in Education at PUCPR. E-mail: diana.pegorini@ifpr.edu.br 
após a promulgação da Lei de Diretrizes e Bases da Educação Nacional - Lei 9394/96, observa-se uma ampliação do acesso. É a partir dessa lei que nos artigos 43 a 57, no capítulo destinado à educação superior, contempla-se a diferenciação de instituições em universidades públicas e privadas, centros universitários, institutos federais e faculdades, o que de certo modo favoreceu a sua ampliação, considerando a possibilidade de criar instituições sem necessidade de pesquisa, extensão e da proporção de 1/3 de docentes em tempo integral e com titulação de mestre e/ou doutor. (BRASIL, 1996). Posteriormente, a criação de programas governamentais destinados ao acesso e à permanência de estudantes também contribuiu para o aumento de matrículas ${ }^{5}$, mas não o suficiente para colocar o Brasil em uma posição confortável, quando comparado a outros países, até mesmo com aos da América do Sul. Observa-se, assim, durante esse período, um crescimento lento, levando a atual taxa líquida para pouco mais de $15 \%$ de jovens de 18 a 24 anos matriculados na educação superior, bem inferior ao que se pretendia já na época do Plano Nacional de Educação (2001-2010). (BRASIL, 2001)

Além do lento crescimento de matrículas na educação superior, existe ainda a evasão, uma problemática que tem se agravado, embora se constate, de modo geral, pouco empenho das instituições de ensino com programas específicos dirigidos para estudantes que abandonam os estudos ou programas que favoreçam a permanência em termos pedagógicos.

A evasão apresenta diferentes causas, tanto de ordem econômica, como aquelas decorrentes da própria instituição. No que se refere às condições econômicas, para muitos, há necessidade de conciliar o curso com o trabalho, o que compromete o tempo de estudo e leva a reprovações. Existe também dificuldade para o pagamento de mensalidades, alimentação, transporte e material didático necessário e, ainda, quando a trajetória escolar não favorece a aprendizagem, levando a reprovações. Por último e não menos importante, existem as expectativas não atendidas dos estudantes com o curso e com a instituição, o modo como se realiza a sua integração no mundo acadêmico e as condições que são oferecidas para a permanência.

Entre as diferentes causas relacionadas à evasão, esse estudo contempla mais especificamente aquelas relacionadas às condições existentes nas IES e busca analisar como a evasão na educação superior vem se manifestando nos últimos 15 anos, utilizando, para isso, dados dos Censos da Educação Superior. A partir desse diagnóstico, discute o

\footnotetext{
${ }^{5}$ De acordo com os dados do INEP/MEC divulgados no Censo da Educação Superior de 2013, a maioria das matrículas encontra-se em Instituições privadas na proporção de 74\% (BRASIL, 2013).
} 
papel das instituições de ensino no que se refere à implementação de ações que possam contribuir para diminuir a evasão. Trata-se de um estudo que contempla uma análise documental, com base em documentos oficiais e legislações vigentes. A análise contempla o contexto da educação superior e a efetividade das políticas em relação às iniciativas governamentais que se relacionam com as possibilidades de ampliar o acesso e favorecer a permanência na educação superior. Na sequência, analisa-se a educação superior na perspectiva da justiça social, de modo a diminuir as disparidades existentes.

\section{Contexto da educação superior}

O acesso à educação superior já carrega em si uma história de discriminação, na qual se constata, como já mencionado, uma elitização desde a criação dos primeiros cursos superiores no período do Brasil Colônia. Embora em termos da legislação observem-se avanços relacionados à ampliação do acesso à educação superior e tenha-se assegurado na Constituição Federal de 1988 (BRASIL, 1988) a educação como um direito de todos, o que também é reafirmado na Lei de Diretrizes e Bases da Educação Nacional - LDBEN - Lei 9394/96 (BRASIL, 1996), ainda assim o acesso é privilégio daqueles que têm melhores condições econômicas.

Não se pode deixar de considerar a importância da criação de programas governamentais a partir de 2004, embora algumas iniciativas de instituições de educação superior e de movimentos sociais são observadas já no início do ano 2000. De acordo com Nascimento (2012, p. 95-97), “[...] a primeira política de cotas para negros numa instituição de ensino superior no Brasil foi instituída nas Universidades Estaduais do Rio de Janeiro (UERJ e UENF) em 2001 [...]. A partir daí outras universidades passaram a adotar políticas de cotas". O autor faz referência ainda ao conceito de ação afirmativa que, “[...] foi forjado pela luta histórica do movimento social negro e da mobilização política promovida pelos Cursos Pré-Vestibular para Negros".

Em temos de política governamental, tem-se a criação do Programa Universidade para Todos (ProUni), um programa do Ministério da Educação, criado pelo Governo Federal em 2004, que concede bolsas de estudo integrais e parciais (50\%), em instituições privadas de ensino superior, em cursos de graduação e sequenciais de formação específica, a estudantes brasileiros (BRASIL, 2005). Além disso, tem-se também o Fundo de Financiamento Estudantil (FIES), um programa do Ministério da Educação, destinado a financiar prioritariamente estudantes de cursos de graduação, regularmente 
matriculados em instituições de ensino não gratuitas, cadastradas no programa com avaliação positiva no SINAES e operacionalizado pelo Fundo Nacional de Desenvolvimento da Educação - FNDE (BRASIL, 2001).

Segundo Paim (2014), o Fies e o ProUni tem apresentado um crescimento significativo, conforme pode-se observar nas Tabelas 1 e 2 a seguir.

Tabela 1 - Bolsas ProUni integrais e parciais ocupadas em instituições privadas de ensino superior no período de 2005-2013

\begin{tabular}{lc} 
Ano & $\mathrm{N}^{\circ}$ \\
\hline 2005 & 95.611 \\
2006 & 204.629 \\
2007 & 310.201 \\
2008 & 434.821 \\
2009 & 596.186 \\
2010 & 748.915 \\
2011 & 919.667 \\
2012 & 1.096 .402 \\
2013 & 1.273 .699 \\
\hline Fonte: PAIM, com base em dados do MEC|SIS ProUni, \\
2014.
\end{tabular}

Tabela 2 - Contratos financiados pelo FIES entre 2010-2014

\begin{tabular}{ll} 
Ano & $\mathrm{N}^{\circ}$ \\
\hline 2010 & 76.000 \\
2011 & 230.000 \\
2012 & 608.000 \\
2013 & 1.100 .000 \\
2014 & 1.500 .000 \\
\hline
\end{tabular}

FONTE: PAIM, com base em dados do MEC|Sis ProUni, 2014.

Em relação ao acesso em instituições públicas, um incentivo importante ocorreu com a aprovação, em 2007, do Plano de Desenvolvimento da Educação (PDE). A partir desse plano, é aprovado o REUNI, pelo Decreto 6.096/2007, que teve como objetivo a ampliação do acesso à educação superior por meio do "Aumento do número de vagas/alunos nas salas de aula [...] abertura de cursos noturnos, diminuição do 
custo/aluno, flexibilidade dos currículos, novas arquiteturas curriculares e ações de combate à evasão" (BRASIL, 2007).

Outra iniciativa do governo foi a criação da Universidade Aberta do Brasil UAB, com o objetivo de implantar um sistema nacional de educação superior a distância, em especial para professores em exercício que não possuem curso superior ou não possuem curso na área de atuação e a formação de novos professores para a educação básica. Segundo Paim (2014), a UAB envolve 104 instituições de ensino superior públicas, 668 polos de apoio presencial e mais de 90 mil concluintes, 35.000 professores da educação básica.

Cabe destacar, ainda, como importante conquista, a aprovação da Lei de Cotas Lei 12.711, de agosto de 2012, regulamentada pelo Decreto 7.824/2012, que "[...] garante a reserva de $50 \%$ das matrículas por curso e turno nas 59 universidades federais e nos 38 institutos federais de educação, ciência e tecnologia a alunos oriundos integralmente do ensino médio público[...]” (Brasil, 2012).

Atualmente, são vários os programas que têm como objetivo assegurar o acesso e a permanência de estudantes na educação superior, como o Programa Nacional de Assistência Estudantil - PNAES, aprovado pelo Decreto 7.234/2010, destinado aos estudantes de instituições públicas federais. De acordo com o Art. $2^{\circ}$, são objetivos do PNAES:

\footnotetext{
I - democratizar as condições de permanência dos jovens na educação superior pública federal;

II - minimizar os efeitos das desigualdades sociais e regionais na permanência e conclusão da educação superior;

III - reduzir as taxas de retenção e evasão; e

IV - contribuir para a promoção da inclusão social pela educação (BRASIL, 2010).
}

Ainda de acordo com o Art. $3^{\circ}$ do referido Decreto, as ações de assistência estudantil do PNAES deverão ser desenvolvidas nas seguintes áreas: moradia, alimentação, transporte, atenção à saúde, inclusão digital, cultura, esporte, creche, apoio pedagógico e acesso, participação e aprendizagem de estudantes com deficiência, transtornos globais do desenvolvimento e altas habilidades e superdotação (BRASIL, 2010). 
Os diferentes programas de assistência estudantil existentes em instituições públicas e os programas e ações voltados à área acadêmica, como o Programa Institucional de Bolsas de Iniciação Científica (PIBIC), Programa de Monitoria, o Programa de Iniciação à Docência (PIBID) e o Apoio à participação em eventos também, de alguma forma, contribuem para a permanência e a melhoria da aprendizagem. No entanto, apesar dos programas, a evasão continua alta, o que sinaliza que não são suficientes ou não são eficientes. Os desafios, portanto, são enormes. Para as IES públicas, no atual contexto de crise econômica e política, o corte de verbas destinadas à educação ameaça os programas e as ações já existentes.

\section{Efetividade das Políticas para Educação Superior}

O Quadro 1 e as Tabelas 3 e 4 deixam evidente dois problemas que mostram a pouca efetividade dos programas governamentais. O primeiro refere-se às matrículas em instituições privadas, pois das 7.305.977 matrículas, 5.373.450 encontram-se na iniciativa privada, o que mostra uma educação superior que depende de pagamento de mensalidades. O segundo grande problema evidenciado é a evasão. Ao se levar em consideração os ingressantes e os concluintes em cursos de quatro anos de duração, por exemplo, observa-se, na Tabela 4, mais de 30\% de evasão, de 2010 a 2013, mas é evidente que depende muito do tipo de curso, pois se evidencia que em alguns quase não há evasão e em outros ela ultrapassa $50 \%$.

Quadro 1 - Resumo - Estatísticas gerais da educação superior, por categoria administrativa, Brasil, 2013

\begin{tabular}{|c|c|c|c|c|c|c|c|c|}
\hline \multirow{3}{*}{$\begin{array}{l}\text { Estatísticas } \\
\text { Básicas }\end{array}$} & \multicolumn{7}{|c|}{ Categoria administrativa } & \\
\hline & \multirow{2}{*}{$\begin{array}{l}\text { Total } \\
\text { Geral }\end{array}$} & \multicolumn{6}{|c|}{ Pública } & \multirow[t]{2}{*}{ Privada } \\
\hline & & Total & Federal & Estad & ual & $\mathrm{Mu}$ & ipal & \\
\hline Número de Instituições & 2.391 & 301 & 106 & 119 & & 76 & & 2.090 \\
\hline \multicolumn{9}{|c|}{ Educação Superior Graduação } \\
\hline \multicolumn{2}{|c|}{ Cursos } & 32.049 & \multicolumn{2}{|c|}{10.850} & \multicolumn{2}{|c|}{5.968} & 3.656 & 1.226 \\
\hline $\begin{array}{l}\text { Matrículas } \\
5.373 .450\end{array}$ & & 7.305 .977 & \multicolumn{2}{|c|}{1.932 .527} & \multicolumn{2}{|c|}{1.137 .851} & 604.517 & 190.159 \\
\hline $\begin{array}{l}\text { Ingresso total } \\
2.211 .104\end{array}$ & \multicolumn{2}{|r|}{2.742 .950} & \multicolumn{2}{|c|}{531.846} & \multicolumn{2}{|c|}{325.267} & 142.842 & 63.737 \\
\hline $\begin{array}{l}\text { Concluintes } \\
761.732\end{array}$ & \multicolumn{2}{|r|}{991.010} & \multicolumn{2}{|c|}{229.278} & \multicolumn{2}{|c|}{115.336} & 82.892 & 31.050 \\
\hline
\end{tabular}




\begin{tabular}{|c|c|c|c|c|c|}
\hline $\begin{array}{l}\text { Curso Superior Sequencial de } \\
\text { Matrículas } \\
16.498\end{array}$ & $\begin{array}{c}\text { ção Específ } \\
16.987\end{array}$ & 489 & 100 & 208 & 181 \\
\hline $\begin{array}{l}\text { Educação Superior - Pós-Grac } \\
31.691\end{array}$ & $\begin{array}{c}\text { Stricto Sen } \\
203.717\end{array}$ & 172.026 & 115.001 & 56.094 & 931 \\
\hline $\begin{array}{l}\text { Educação Superior Total } \\
\text { Matrícula Total } \\
5.421 .639\end{array}$ & 7.526 .681 & 2.105 .042 & 1.252 .952 & 660.819 & 191.271 \\
\hline $\begin{array}{l}\text { Funções Docentes em Exercício } \\
212.063 \\
\text { (1) e (2) }\end{array}$ & 367.282 & 155.219 & 95.194 & 48.275 & 11.750 \\
\hline $\begin{array}{l}\text { Docentes em Exercícios } \\
181.302 \\
\text { (2) e (3) }\end{array}$ & 321.700 & 152.166 & 94.354 & 47.823 & 11.459 \\
\hline
\end{tabular}

Fonte: MEC/INEP - MEC/CAPES; Inep/Deed.

Em relação ao acesso, observa-se, pelo Censo da Educação Superior de 2013, um aumento significativo no número de universidades entre o período de 2002 (45 universidades) e 2014 (63 universidades) (PAIM, 2014), mas a Tabela 3 evidencia que $87,4 \%$ das IES são privadas e somente $12,6 \%$ são públicas, o que dificulta o ingresso de estudantes por dificuldades de ordem econômica.

Tabela 3 - Número e percentual de instituições de educação superior, por categoria administrativa - Brasil - 2013

\begin{tabular}{c|c|c|c|c|c|c|c|c|c}
\hline \multicolumn{2}{c|}{ Total Geral } & \multicolumn{8}{c}{ Categoria Administrativa } \\
\hline Total Geral & $(\%)$ & Federal & $(\%)$ & Estadual & $(\%)$ & Municipal & $(\%)$ & Privada & $(\%)$ \\
\hline 2.391 & 100 & 106 & 4,4 & 119 & 5,0 & 76 & 3,2 & 2.090 & 87,4 \\
\hline
\end{tabular}

Fonte: MEC/INEP

Esta configuração da educação superior evidenciando ser majoritariamente privada dificulta o acesso e a permanência dos jovens na educação superior, mas a ampliação da oferta de vagas muitas vezes é utilizada para levar ao entendimento de que o acesso depende tão somente de esforço individual. Segundo Oliveira (2013, p. 273):

A história do acesso à educação superior no Brasil revela uma tensão permanente entre continuidade e ruptura com os mecanismos de seletividade social, mas com prevalência da continuidade dos modelos ou processos de seleção dos melhores, segundo as capacidades individuais, ainda que embasado, em geral, no discurso da igualdade de oportunidades e mesmo da democratização do acesso. 
Observa-se pela Tabela 4 que houve um aumento de 54,5\% de matrículas considerando o período de 2003 a 2013, mas que não atende ao percentual de jovens sem educação superior no país e revela uma defasagem significativa quando considerada a relação ingressantes e concluintes, o que indica elevada evasão. Dados do Inep evidenciam ainda que do total de matrículas, $67 \%$ são de cursos de bacharelado, 18, $9 \%$ de cursos de licenciatura e 13,7\% de tecnologia. Ocorreu um crescimento entre 2012 e 2013 de 3,8\%, sendo 4,4\% nos bacharelados, 0, 6\% nas licenciaturas e 5,4\% nos tecnológicos, mas também ocorreu uma redução de 5,7\% nos concluintes.

Tabela 4 - Número de cursos, matrículas, concluintes e ingressos na educação superior, 2013

\begin{tabular}{c|c|c|c|c}
\hline \multirow{2}{*}{ Ano } & \multicolumn{4}{|c}{ Total Geral: Graduação e Sequencial } \\
\cline { 2 - 5 } & Cursos & Matrículas & Concluintes & Ingressos \\
\hline 2003 & 17.380 & 3.989 .366 & 554.230 & 1.591 .654 \\
2004 & 19.592 & 4.278 .133 & 652.560 & 1.682 .419 \\
2005 & 21.459 & 4.626 .740 & 756.911 & 1.851 .255 \\
2006 & 23.257 & 4.944 .877 & 784.218 & 1.998 .163 \\
2007 & 24.653 & 5.302 .373 & 806.419 & 2.165 .103 \\
2008 & 26.059 & 5.843 .322 & 885.586 & 2.360 .035 \\
2009 & 28.966 & 5.985 .873 & 967.558 & 2.081 .382 \\
2010 & 29.737 & 6.407 .733 & 980.662 & 2.196 .822 \\
2011 & 30.616 & 6.765 .540 & 1.022 .711 & 2.359 .409 \\
2012 & 30.050 & 7.058 .084 & 1.056 .069 & 2.756 .773 \\
2013 & 32.197 & 7.322 .964 & 994.812 & 2.749 .803 \\
\hline
\end{tabular}

Fonte: MEC/INEP - MEC/CAPES; Inep/Deed.

Em relação ao percentual do PIB, o gasto público total do Brasil com a educação no ano de 2011, segundo a OCDE (2014), foi de 6,1\%, acima da média dos países da OCDE, que foi de 5,6\%. No entanto, quando calculado por estudante o gasto público em instituições públicas, de todos os níveis educacionais combinados, verifica-se que ele foi de 2.985 dólares, bem abaixo da média da OCDE, que foi de 8.952 dólares, sendo esse o segundo valor mais baixo de todos os países-membros e parceiros da OCDE.

Conforme explica Amaral (2013a, p. 3),

Para uma análise completa do quadro político, quando se trata da utilização desse indicador - percentual do PIB - há necessidade da utilização de duas outras informações: o valor do PIB do país e o tamanho do alunado a ser atendido, o que pode ser expresso, por exemplo, pela quantidade de pessoas do país que estão em idades educacionais corretas. 
O autor apresenta uma comparação entre o percentual do PIB aplicado à educação pela Bolívia, de 6,4\%, e o Canadá, de 5,2\%, e demonstra que quando analisado o valor do PIB/PPP, os recursos em educação e a população em idade educacional, percebe-se que a Bolívia aplicou 695,00 US\$ e o Canadá 7.731,00 US\$ por pessoa em idade educacional, o que indica que somente considerar o PIB na comparação com outros países não permite conclusões sobre quem vem investindo mais na educação. Com a aprovação no novo Plano Nacional de Educação da Meta 20, está prevista a aplicação de $10 \%$ do PIB para a educação até o final do decênio, que comparado com os percentuais anteriores, significa uma importante conquista. Conforme Amaral (2013a, p.9 e 10), “[...] dificilmente um país consegue aplicar mais de 10\% do PIB" na educação, no entanto, se comparado com outros países, o Brasil deveria “[...] multiplicar por quase cinco os valores atuais para a educação", o que significaria em torno de 20\% do PIB. Antes de chegar aos $10 \%$, consta no PNE que o valor vai chegar a $7 \%$ do PIB até o final do $5^{\circ}$ ano de vigência do PNE, o que evidencia ainda recursos insuficientes para a educação.

Além das dificuldades de acesso à educação superior relacionadas, em especial, às de ordem econômica, ainda existem as deficiências decorrentes da trajetória escolar de muitos estudantes. Mesmo assim, muitos dos que conseguem o ingresso na educação superior abandonam o curso antes do seu término, pois são estudantes que não conseguem concluir seu curso, quer em instituições públicas quer nas instituições privadas, já que em ambas se observa a evasão, embora com diferenças.

Segundo Silva Filho et al. (2007, p. 642), existem duas formas de evasão que são similares, mas não idênticas:

1. A evasão anual média mede qual a porcentagem de alunos matriculados em um sistema de ensino, em uma IES, ou em um curso que, não tendo se formado, também não se matriculou no ano seguinte (ou no semestre seguinte, se o objetivo for acompanhar o que acontece em cursos semestrais). Por exemplo se uma IES tivesse 100 alunos matriculados em certo curso que poderiam renovar suas matrículas no ano seguinte, mas somente 80 o fizessem, a evasão anual média no curso seria de $20 \%$.

2. A evasão total mede o número de alunos que, tendo entrado num determinado curso, IES ou sistema de ensino, não obteve o diploma ao final de um certo número de anos. É o que se chama índice de titulação. Por exemplo, se 100 estudantes entraram em um curso em um determinado ano e 54 se formaram, o índice de titulação é de 54\% e a evasão nesse curso é de $46 \%$.

O que poderia levar os estudantes, após vencer os obstáculos para ingressar na educação superior, a abandonar seu curso? Sabe-se que são múltiplos os motivos que levam os estudantes a desistir dos cursos e que estes relacionam-se tanto a fatores econômicos como a fatores decorrentes do ambiente acadêmico. No estudo realizado por 
Estrada; Radaelli (p.43-4), em pesquisa realizada junto a estudantes observaram que os fatores que levaram a evasão ou trancamento de curso foram:

$65 \%$ por questão financeira [...], 10\% em decorrência do tempo de conclusão do curso, $3 \%$ pelo período/turno do curso, $5 \%$ por não ser o curso que desejaria seguir carreira, $2 \%$ pela visibilidade econômica que o curso proporciona, $10 \%$ por não conseguir conciliar trabalho e estudo e 5\% por não conseguir auxílio da assistência estudantil

No estudo realizado por Morosini et al. (s.d.), “A evasão na educação superior no Brasil: uma análise da produção de conhecimento nos periódicos Qualis entre 20002011 " , foram identificados somente sete trabalhos especificamente sobre evasão e a partir da análise desses estudos os autores apresentam um detalhamento das causas da evasão indicadas nas pesquisas realizadas como sendo:

1. Aspectos financeiros relacionados à vida pessoal ou familiar do estudante;

2. Aspectos relacionados à escolha do curso, expectativas pregressas ao ingresso, nível de satisfação com o curso e com a universidade;

3. Aspectos interpessoais - dificuldades de relacionamento com colegas e docentes;

4. Aspectos relacionados com o desempenho nas disciplinas e tarefas acadêmicas - índices de aprovação, reprovação e repetência;

5. Aspectos sociais, como baixo prestígio social do curso, da profissão e da universidade elegida;

6. Incompatibilidade entre os horários de estudos com as demais atividades, como, por exemplo, o trabalho;

7. Aspectos familiares como, por exemplo, responsabilidade com filhos e dependentes, apoio familiar quanto aos estudos etc.;

8. Baixo nível de motivação e compromisso com o curso.

Das oito causas indicadas pelos autores, observa-se que mais de $50 \%$ são problemas relacionadas à vida acadêmica, como motivação, relacionamentos e desempenho nas disciplinas do curso. No caso do desempenho nas disciplinas e tarefas acadêmicas, isto é, com a reprovação e a repetência que se refere ao processo pedagógico, observa-se que não se tem conseguido dar o suporte necessário àqueles alunos com maior dificuldade.

\footnotetext{
${ }^{6}$ De acordo com Morosini, Casartelli, Silva, Santos, Schmitt, Gessinger, a busca foi realizada em periódicos classificados como A1, A2, B1, B2, a partir do Portal de Periódicos CAPES e do sistema Scientific Eletronic Library Online (SCIELO). Segundo os autores, a maioria dos estudos sobre evasão está voltado para a Educação Básica, sendo ainda poucos os estudos sobre educação superior. Dos sete trabalhos encontrados sobre evasão na educação superior, cinco se referiam a um determinado curso, um sobre uma instituição e outro sobre a evasão no contexto brasileiro com base no Censo da educação. Disponível em: <http://clabesalfaguia.org/clabes-2011/ponencias/ST_1_Abandono/12_MorosiniM_Abandono_ESBrasil.pdf >. Acesso em: 17 maio 2015
} 
O problema é que a qualidade da educação, seja no nível básico como no superior, é aferida mediante avaliação de larga escala e com a ampliação e a complexidade da educação superior a avaliação tem assumido uma perspectiva regulatória, com base na Lei 10.861/2004, que institui o Sistema Nacional de Avaliação da Educação Superior (SINAES). Conforme Sousa e Bruno (2008) apud Sousa Real (2013, p. 71), “[...] o intento de regulação em um contexto mais geral de desigualdade, tende a, no mínimo, mantê-la, se não intensificá-la, considerando o estágio atual do capitalismo". Nessa perspectiva, não se pode utilizar a avaliação como critério para aferir a qualidade da educação superior.

Amaral (2013b, p. 316-17), ao discutir o financiamento da educação, tem problematizado o conceito de qualidade e considera que existe uma "[...] complexidade intrínseca à discussão sobre a qualidade da educação superior" e explica que isso ocorre:

\begin{abstract}
Primeiro pela proximidade existente entre esse nível educacional e a fronteira do conhecimento - onde impera o imprevisível -; segundo, pela multiplicidade de áreas de conhecimento em que cada uma delas exige um conjunto específico de insumos para ser possível afirmar que ali há certa qualidade; e, terceiro, pelo vínculo direto entre conhecimento existente nesse nível educacional e os problemas enfrentados pela sociedade nas mais diversas necessidades.
\end{abstract}

Outro aspecto apontado pelo autor refere-se à dificuldade em atender o que os diferentes agentes relacionados à educação superior entendem por qualidade: governantes, universidades, estudantes e empresários. Observa-se, de fato, que os objetivos mudam conforme a área de atuação: dos governantes, que formulam as políticas educacionais; das instituições de educação superior, que indicam as suas finalidades no projeto pedagógico institucional e que esperam sucesso nas avaliações em larga escala conduzidas pelo governo; dos estudantes, que esperam adquirir competências para o mercado de trabalho; dos empresários, que esperam profissionais preparados para atuar de modo a contribuir com o seu crescimento num mundo competitivo. Não sendo possível atender a todos, as instituições de educação superior deveriam definir qual profissional e para qual sociedade se deseja conduzir o processo pedagógico e criar as condições ${ }^{7}$ necessárias para efetivar o processo de formação na direção estabelecida.

O problema, segundo Silva (2009, p. 222-223), é que:

\footnotetext{
${ }^{7}$ Sobre as condições que a educação superior precisaria satisfazer, ver: AMARAL, Nelson Cardoso. Os recursos financeiros aplicados nas universidades federais nos governos de FHC e Lula e um olhar sobre a qualidade. In: SOUSA, J. V. (Org.). Educação superior: cenários, impasses e propostas. Campinas: Autores Associados, 2013, p. 315-341.
} 
A concepção de qualidade assentada na racionalidade técnica e nos critérios econômicos serviu e serve de referência para a formulação de políticas para a educação pública no país. Assim, a atualização da teoria do capital humano pelos técnicos e arautos do Banco Mundial tornou-se, para alguns governos e gestores, o norte que orienta as políticas para a educação básica e superior assentadas no conceito de qualidade advindo das bases de teorias econômicas.

É evidente que o poder de interferir na formulação de políticas educacionais muda conforme o poder que se possui. No contexto da globalização econômica, as instituições de educação superior são diretamente atingidas em razão da competividade entre as empresas e a ênfase recai sobre a aquisição de competências na perspectiva da racionalidade técnica. Conforme afirmam Lima, Cunha e Santos (2013, p. 92):

\begin{abstract}
Essas mudanças, por um lado, são benéficas à construção da world class university, isto é, uma instituição para o mundo desenvolvido e globalizado na qual os recursos são abundantes, alunos e professores devem demonstrar excelência e a gestão é um meio regulamentar de apoio, autonomia, liderança e liberdade acadêmica. Mas ao mesmo tempo, elas são questionáveis para a educação dos sujeitos como seres humanos que, portanto, precisam ser objetos de análise e crítica.
\end{abstract}

Os autores ainda chamam a atenção para as contradições vivenciadas pelas universidades que não podem desconsiderar seu papel no desenvolvimento social e econômico, mas têm compromisso, também, com uma postura crítica no que se refere às finalidades do processo de formação. Uma das manifestações muito evidentes da influência do atual contexto econômico, conforme indicado por Leite (2010 In: Lima; Cunha; Silva, 2013, p. 93), são as características que vêm assumindo os grupos de pesquisa que hoje são altamente incentivados para ter apoio de agências de fomento e/ou de empresas e que assumem características de verdadeiras "microempresas de pesquisa". Como diria Foucault (2008) o homem torna-se empresário de si próprio e nos dizeres de Jantsch (2010, p. 63), “[...] não há como desconsiderar que tanto a educação formal como um todo, quanto a pesquisa universitária em particular se realizam sob a sociabilidade do capital [...] e, portanto, cada vez mais sob critérios mercadológicos".

Assim, a qualidade da educação superior vem sendo compreendida como aquela que mais atende às expectativas, do que vem sendo enfatizado pelos organismos internacionais alinhados ao campo econômico. Nesse contexto, são definidas as competências a serem adquiridas pelos estudantes e a preocupação com a formação e a emancipação humana não tem prioridade, vale a premissa de que vençam os melhores. 
Balsa (2008, p. 249) afirma que "O ensino superior, como aliás qualquer sistema de ensino, não se limita, [...] a espelhar a sociedade na qual ela se insere. No processo de construção das sociedades, o ensino espelha e, ao mesmo tempo, produz a imagem”.

Ainda conforme Balsa (2008, p. 249):

\begin{abstract}
Acreditamos que as funções que o ensino superior realiza através dos investimentos dos seus diferentes atores [...] só podem ser entendidas na intersecção entre as forças que lhes permitem produzir e ao mesmo tempo reproduzir sentidos e dispositivos sociais. No entanto, o reconhecimento desta dupla funcionalidade não nos dispensa de escrutinar a tensão que se estabelece, através dos diferentes momentos e níveis do ensino considerados, entre as forças de produção e as forças de reprodução presentes, sempre, no campo do ensino superior.
\end{abstract}

\title{
Considerações finais
}

Considerando que a educação superior constitui-se em uma das principais condições para a mobilidade social à medida que no atual contexto social cada vez mais o diploma é requisito no mercado de trabalho, as dificuldades de acesso e permanência apresentam-se como um grande desafio. Assim, quando os estudantes que conseguem ingressar na educação superior não permanecem e não concluem com sucesso o curso escolhido, é preciso repensar a educação superior, suas políticas, a organização, a gestão e o processo pedagógico das instituições de educação superior. O esforço dos programas governamentais de acesso e permanência requer a atuação conjunta das instituições e exigem um olhar especial para aqueles estudantes que, em decorrência de dificuldades econômicas, tiveram uma trajetória de escolaridade e de vida que não favorecem o sucesso nos cursos que escolherem ou que foi possível escolher.

A efetiva democratização da educação deve vir acompanhada de medidas que auxiliem os estudantes e contribuam para minimizar as situações de repetência e evasão, de modo a contribuir com maior justiça social. Para tanto se faz necessário maior preocupação das instituições de ensino com a inclusão e que, portanto, precisam ser criadas condições para a permanência e o sucesso dos estudantes na educação superior, quando estes apresentam dificuldades decorrentes da sua trajetória de escolarização. Trata-se de uma educação com qualidade social, que segundo Silva $(2009$, p. 225) é,

[...] aquela que atenta para um conjunto de elementos e dimensões socioeconômicas e culturais que circundam o modo de viver e as expectativas das famílias e de estudantes em relação à educação; que busca compreender as políticas governamentais, os projetos sociais e ambientais em seu sentido político, voltados para o bem comum; que luta por financiamento adequado, pelo reconhecimento social e valorização dos trabalhadores em educação; que 
transforma todos os espaços físicos em lugar de aprendizagens significativas e de vivências efetivamente democráticas. (SILVA, 2009, p. 225).

Uma educação superior que tenha como prioridade viabilizar a "igualdade de resultados" que, de acordo com Draibe (1990, p. 4, destaque da autora), significa “[...] uma concepção de direitos que devem ser garantidos igualmente a todos os cidadãos", não se trata de propor políticas que buscam gerar uma "igualdade de oportunidades" que valoriza o mérito, pois estas “[...] têm o significado de respeitar as 'diferenças' e no limite legitimar a desigualdade”. Significa o compromisso das instituições de ensino de buscar formas de atender a todos os estudantes, propiciando apoio pedagógico, ambiente democrático e respeito aos princípios da ética e de justiça.

\section{Referências}

AMARAL, Nelson Cardoso. O novo PNE e o financiamento da educação no brasil: os recursos como um percentual do PIB. UNICAMP. Campinas/SP. 2013a. Disponível em: $<$ http://www.cedes.unicamp.br/seminario3/nelson_amaral.pdf $\rangle_{-}$AAcesso em : 6 jan.

2015.

AMARAL, Nelson Cardoso. Os recursos financeiros aplicados nas universidades federais nos governos de FHC e Lula e um olhar sobre a qualidade. In: SOUSA, J. V. (Org.). Educação superior: cenários, impasses e propostas. Campinas: Autores Associados, 2013b. p. 315-341.

BALSA, Casemiro. Processo de democratização e acesso ao ensino superior em Portugal. In: AMARAL, Alberto (Coord.). Políticas de ensino superior: quatro temas em debate. Seminário de Ensino Superior. Lisboa: Conselho Nacional de Educação, 2008. p. 249289.

BRASIL. Constituição (1988) Constituição da República Federativa do Brasil. Brasília, DF: Senado Federal, 1988. Relatório Oficial

BRASIL. Lei 9394 de 20 de dezembro. Estabelece as diretrizes e bases da educação nacional. Diário Oficial da República Federativa do Brasil, Brasília DF, v.13, n. 258, p. 27833 de 23 dez de 1996.

BRASIL. Lei no 10.172 de 9 de janeiro de 2001. Aprova o Plano Nacional de Educação e dá outras providências. Diário Oficial da República Federativa do Brasil, Brasília, DF, n. 7, p.1, Brasília, DF, 10 de janeiro de 2001. Seção 1.

BRASIL. Lei 10.260 de 12 de julho de 2001. Dispõe sobre o Fundo de Financiamento ao Estudante do Ensino Superior e dá outras providências. Publicado no Diário Oficial da República Federativa do Brasil, Brasília, DF, n. 134, p. 2, 13 de julho de 2001. Seção 1. 
BRASIL. Lei 11.096 de 13 de janeiro de 2005. Institui o Programa Universidade para Todos - PROUNI. Publicado no Diário Oficial da República Federativa do Brasil, Brasília, DF, n. 10, p. 11, 14 de janeiro de 2005. Seção 1.

BRASIL. Decreto n. 6.096 de 24 de abril de 2007. Institui o Programa de Apoio a Planos de Reestruturação e Expansão das Universidades Federais - REUNI. Publicado no Diário Oficial da República Federativa do Brasil, Brasília, DF n. 79, p.7, em 25 de abril de 2007. Seção1

BRASIL. Decreto 7.234 de 19 de julho de 2010. Dispõe sobre o Programa Nacional de Assistência Estudantil - PNAES. Presidência da República Federativa do Brasil. Brasília, DF, n.137, p.5, 20 de julho de 2010. Seção 1.

BRASIL. Lei 12.711 de 29 de agosto de 2012. Dispõe sobre o ingresso nas universidades federais e nas instituições federais de ensino técnico de nível médio e dá outras providências. Publicado no Diário Oficial da República Federativa do Brasil, Brasília, DF, n. 169, 30 de agosto de 2012. Seção 1

BRASIL. Ministério da Educação. INEP. Censo da Educação Superior de 2013. Disponível em: <http://portal.inep.gov.br>. Acesso em: 7 set. 2014.

BRASIL. MEC. Lei 13.005 de 25 de junho de 2014. Dispõe sobre o Plano Nacional de Educação. Publicado no Diário Oficial da República Federativa do Brasil, Brasília, DF n. 120-A, 26 de junho de 2014. Seção 1.

DRAIBE, Sônia Miriam. As políticas sociais brasileira: diagnósticos e perspectivas. Para a década de 90: prioridades e perspectivas de políticas públicas. IPEA, Instituto de Planejamento Econômico e Social; IPLAN, Instituto de Planejamento. Brasília, IV Políticas e Organização do Trabalho, março, 1990.

ESTRADA, Adrian Alvarez; RADAELLI, Andressa. A política de assistência estudantil em uma universidade pública: a perspectiva estudantil. Revista Eletrônica de Política e Gestão Educacional. UNESP, n. 16, $1^{\circ}$ semestre de 2014. P. 32-47

FOUCAULT, Michel. Nascimento da biopolítica: curso dado no Collège de France (1978-1979). São Paulo: Marins Fontes, 2008.

JANTSCH, Ari Paulo. Mercadorização, formação, universidade pública e pesquisa crítico-emancipatória: em tempo de realização plena do conceito de capital. In: OLIVEIRA, J. F.; CATANI, A. M.; SILVA JÚNIOR, J. R. (Org.). Educação superior no Brasil: em tempos de internacionalização. São Paulo: Xamã, 2010. p. 55-78.

LIMA, Elizeth Gonzaga dos Santos; CUNHA, Flávio Luiz Silva Jorge; SILVA, Jaime Santana Orro. Sistema Nacional de Avaliação da Educação Superior (SINAES). In: SOUSA, J. V. (Org.) Educação superior: cenários, impasses e propostas. Campinas: Autores Associados, 2013. p. 91-111. 
MOROSINI, Marília Costa; CASARTELLI, Alam de Oliveira; SILVA, Ana Cristina Benso; SANTOS, Betina Steren; SCHMITT, Rafael Eduardo; GESSINGER, Rossana Maria. A evasão na educação superior no Brasil: uma análise da produção de conhecimento nos periódicos Qualis entre 2000-2011. Disponível em: <http://www.alfaguia.org/>. Acesso em: 17 maio 2015.

NASCIMENTO, Alexandre. As políticas de cotas para o acesso de negros ao ensino superior no Brasil e a importância dos cursos pré-vestibulares para negros na sua consolidação. IX Seminário Nacional de Estudos, Pesquisas "História, Sociedade e Educação no Brasil". Anais. Universidade Federal da Paraíba - João Pessoa, 31/07 a 03/08/2012. Disponível em: <http://www.histedbr.fe.unicamp.br/acer_histedbr/seminario/seminario9/PDFs/2.58.pdf >. Acesso em: 8 set. 2014.

OCDE. Education at a glance 2014. Country note. Disponível em: <http://www.oecd.org/edu/Brazil-EAG2014-Country-Note-portuguese.pdf>. Acesso em: 1 nov. 2014.

OLIVEIRA, João Ferreira. Acesso à educação superior no Brasil: ente o elitismo e as perspectivas de democratização. In: SOUSA, J. V. (Org.). Educação superior: cenários, impasses e propostas. Campinas: Autores Associados, 2013. p. 274-313.

PAIM, Henrique. Audiência pública na Comissão de Educação, Cultura e Esporte do Senado Federal. Censo da Educação Superior 2013.Disponível em: <www19.senado.gov.br/sdleg-getter/public/getDocument?docverid>. Acesso em: 28 out. 2014.

SHIROMA, Oto Eneida; MORAES, Maria Célia Marcondes; EVANGELISTA, Olinda. Política educacional. 4. ed. Rio de Janeiro: Lamparina, 2011.

SILVA, Maria Abadia. Qualidade social da educação pública: algumas aproximações. Caderno CEDES, Campinas, v. 29, n. 78, p. 216-226, maio/ago. 2009.

SILVA FILHO, Roberto Leal Lobo; MOTEJUNAS, Paulo Roberto; HIPÓLITO, Oscar; LOBO, Maria Beatriz de Carvalho Melo. A evasão no ensino superior brasileiro.

Cadernos de Pesquisa, v. 37, n. 132, set. /dez., 2007, p. 641-659.

SOUZA, Mariane Pereira; REAL, Giselle Cristina Martins. Avaliação da educação superior na intersecção de políticas sistêmicas. In: CUNHA, C.; SOUSA, J. V.; SILVA, M. A. Educação superior: cenários, impasses e propostas. Campinas: Autores Associados, 2013, p. 61-89 